\title{
Hypogonadism in chronic liver disease: impaired release of luteinising hormone
}

\author{
P BANNISTER, TINA HANDLEY, C CHAPMAN, M S LOSOWSKY
}

\begin{abstract}
Alcohol abuse leads to impotence, infertility, and feminisation. Patients with chronic alcoholism may have impaired hypothalamic-pituitary function. The release of luteinising hormone was investigated in men with alcoholic cirrhosis with and without hypogonadism and controls. Blood was sampled every 15 minutes for six or eight hours and luteinising hormone concentrations measured by radioimmunoassay. Data were analysed by iterative computerised analysis and spectral analysis to assess pulsatile release and the length of the cycle, respectively. Pulsatile release of luteinising hormone was shown in all the control subjects; in the men with alcoholic liver disease it was normal in those with subclinical primary testicular failure but absent or grossly attenuated in those with overt combined central and primary gonadal failure.

The impaired release of luteinising hormone in the men with overt gonadal failure might be due to a hypothalamic defect.
\end{abstract}

\section{Introduction}

Alcoholic liver disease may lead to impotence, infertility, and feminisation in men and amenorrhoea in women. ${ }^{12}$ Ethanol has a direct toxic effect on the gonads, causing impaired spermatogenesis and abnormal morphology of Leydig's cells, ${ }^{3}$ but data on hypothalamic-pituitary function in alcoholic liver disease are conflicting. Basal plasma luteinising hormone concentrations are normal, but response to clomiphene is attenuated and testosterone concentrations are low. ${ }^{45}$ The release of luteinising hormone is pulsatile, ${ }^{6}$ and

Department of Medicine, St James's University Hospital, Leeds LS9 7TF P BANNISTER, MB, MRCP, research fellow M S LOSOWSKY, MD, FRCP, professor

Department of Nuclear Medicine, General Infirmary, Leeds TINA HANDLEY, BSC, medical laboratory scientific officer C CHAPMAN, PHD, principal biochemist

Correspondence to: Dr Bannister. a contributory factor to the above findings may be impaired release of the hormone. The present study was designed to test this hypothesis.

\section{Subjects and methods}

We studied two groups of patients. One comprised four men (aged 32-53) with chronic alcoholic liver disease and no clinical signs of gonadal failure, and the other comprised five men (aged 38-62) with alcoholic liver disease and clinical signs of hypogonadism. All patients had histologically proved cirrhosis of the liver. The presence or absence of hypogonadism was assessed clinically. Testicular atrophy (testicular volume less than $10 \mathrm{ml}$ ), loss of pubic and axillary hair, and a reduced frequency of shaving were noted in all five men with overt hypogonadism. All nine patients had stable liver disease and had not changed their drug treatment in the three weeks before the study day.

Table I gives details of the patients. Hepatomegaly was assessed on a three point scale: $+=$ less than $5 \mathrm{~cm}$ below the costal margin, $++=5-10 \mathrm{~cm}$ below the costal margin, $+++=$ more than $10 \mathrm{~cm}$ below the costal margin. Splenomegaly was assessed clinically: $+=$ palpable spleen,$+++=$ gross splenomegaly. Portal hypertension and hepatic encephalopathy were as sessed clinically on a scale of + to +++ . No laboratory measurements of these two variables were undertaken.

A venous cannula was sited in a forearm vein. After a 30 minute rest venous blood was sampled every 15 minutes for eight hours in seven of the nine patients and, owing to technical problems, for six hours in the two others.

TABLE I-Details of patients studied

\begin{tabular}{lccc}
\hline Case & Age & Portal & Testicular \\
No & (years) & Hepatomegaly Splenomegaly & hypertension \\
Encephalopathy volume $(\mathrm{ml})$
\end{tabular}

No (years) Hepatomegaly Splenomegaly hypertension Encephalopathy volume (ml

\begin{tabular}{lllllll}
\hline \multicolumn{7}{c}{ Subclinical primary testicular failure } \\
1 & 32 & ++ & + & + & - & 15 \\
2 & 39 & + & - & + & - & 16 \\
3 & 45 & ++ & + & + & - & 18 \\
4 & 53 & + & + & - & - & 18 \\
& & & Overt gonadal failure & & \\
5 & 38 & + & + & + & - & 9 \\
6 & 43 & + & - & - & - & 9 \\
7 & 45 & + & + & - & - & 7 \\
8 & 62 & ++ & + & + & - & 8 \\
9 & 41 & ++ & + & + & - & 7 \\
\hline
\end{tabular}


Healthy male controls recruited from a volunteer population and matched for age (to within three years) and duration of sampling (six or eight hours) were also studied.

\section{RADIOIMMUNOASSAY}

Luteinising hormone was measured by a double antibody radioimmunoassay using macrogol assisted double antibody precipitation. Concentrations of luteinising hormone were expressed in IU/l in terms of MRC standard 68/40. The mean intra assay coefficient of variation of the usable portions of the standard curve was $3 \cdot 1 \%$ and the mean inter assay coefficient of variation $3 \cdot 1 \%$.

Androgens - The androgens testosterone, androstenedione, and dehydroepiandrosterone sulphate were measured with a single antibody radioimmunoassay. The plasma steroids were extracted from an appropriate dilution of serum with ether. The ether was dried down and the residue resuspended in buffer. All steroids were measured in the aqueous phase using ligands labelled with tritium. The specificity of the antisera and inter assay and intra assay coefficients of variation have been reported previously. ${ }^{7}$

\section{STATISTICAL ANALYSIS}

Data from each group were compared for significant differences by the Mann-Whitney $U$ test. Two methods were used to analyse the data for appreciable pulses of luteinising hormone.

Iterative pulse analysis-Discrete pulses were detected with a computer, using an iterative process to distinguish the pulses of maximum amplitude. ${ }^{8}$ This method is a variation on the threshold technique. Pulses are deemed appreciable if they exceed the threshold by a predetermined amount (usually related to the coefficient of variation of the assay). The method can be used to analyse both irregular and regular rhythms. It has the advantage over simple visual analysis of data that observer bias is removed, and it allows pulses to be detected when background noise is fairly high. In the program used the threshold was adjusted for each set of data, thus improving the detection of pulses against background noise. The analysis provided an estimate of the ratio of signal to noise; it is recommended that data should not be analysed if this ratio is less than $4: 1$ in experiments containing 18-35 samples.

Spectral analysis - A disadvantage of threshold techniques is that patterns of secretion of hormones with a long cycle-for example, diurnal vari- ation-are not detected. Spectral analysis, also called time series analysis, 揑 a mathematical method for estimating the patterns or harmonics of wav forms, which if summed would reproduce the original data. It can detes both fast and slow wave forms, though it is more useful for detecting slow wave forms. This method of analysis permits measurement of release of hormones that is non-pulsatile and of low frequency. The method of Murdoch et al was used. ${ }^{9}$ The results of the analysis were expressed as $\vec{a}$ periodogram, which portrayed all the data collected, both appreciable harmonics (or patterns of release) and the background noise. An assessmerff of the significance of the data was included in the computer program Briefly, this was a $95 \%$ one sided tolerance limit that was added to the periodogram; any harmonics above the tolerance limit were significant at probability of $0.05 .^{9}$ This allowed the significance of the detected harmonics above the background noise to be assessed (fig 1).

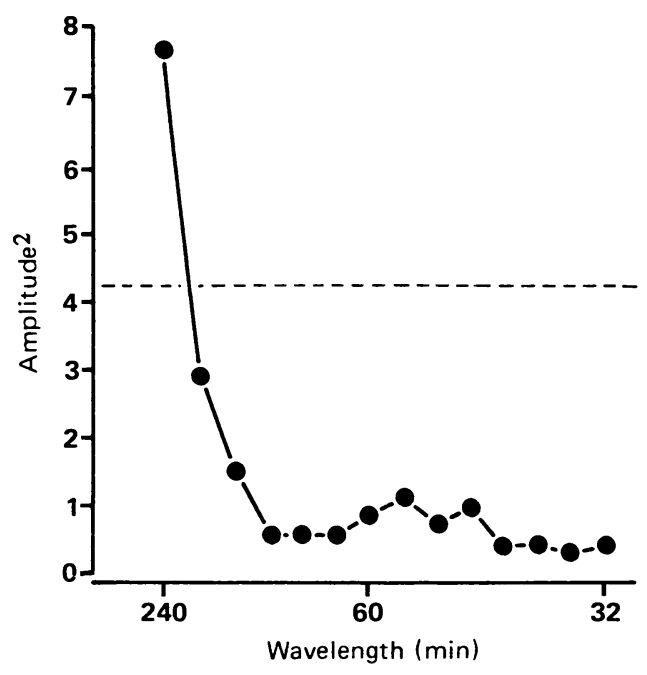

FIG 1-Periodogram obtained by spectral analysis in case 2. Appreciable pulses of a given wavelength are those above the dotted line, which represents $95 \%$ tolerance limits.

TABLE II-Mean androgen concentrations (and ranges) in the two groups of patients and their controls

\begin{tabular}{|c|c|c|c|}
\hline & $\begin{array}{l}\text { Testosterone } \\
\quad(\mathrm{nmol} /)\end{array}$ & $\begin{array}{l}\text { Androstenedione } \\
(\mathrm{nmol} / \mathrm{l})\end{array}$ & $\begin{array}{c}\text { Dehydroepiandrosterone } \\
\text { sulphate } \\
(\mu \mathrm{mol} / 1)\end{array}$ \\
\hline $\begin{array}{l}\text { Patients with overt gonadal failure } \\
\text { Controls }\end{array}$ & $\left.\begin{array}{c}4 \cdot 5(3 \cdot 0-7 \cdot 0) \\
15 \cdot 2(12 \cdot 0-17 \cdot 0)\end{array}\right\} p<0 \cdot 01$ & $\left.\begin{array}{r}7 \cdot 8(6 \cdot 0-12 \cdot 0) \\
3 \cdot 9(2 \cdot 0-5 \cdot 7)\end{array}\right\} \mathbf{p}<0.05$ & $\left.\begin{array}{l}1 \cdot 6(0 \cdot 5-3 \cdot 0) \\
6 \cdot 1(3 \cdot 4-7 \cdot 6)\end{array}\right\} \mathrm{p}<0.01$ \\
\hline $\begin{array}{l}\text { Patients with subclinical primary testicular failure } \\
\text { Controls }\end{array}$ & $\left.\begin{array}{c}7 \cdot 4(6 \cdot 0-9 \cdot 0) \\
17 \cdot 0(14 \cdot 0-21 \cdot 0)\end{array}\right\} p<0 \cdot 05$ & $\left.\begin{array}{l}9 \cdot 4(7 \cdot 0-14 \cdot 0) \\
5 \cdot 1(3 \cdot 0-8 \cdot 0)\end{array}\right\} \mathrm{p}<0 \cdot 05$ & $\left.\begin{array}{l}2 \cdot 1(0 \cdot 7-4 \cdot 4) \\
6 \cdot 9(4 \cdot 3-8 \cdot 1)\end{array}\right\} p<0 \cdot 05$ \\
\hline
\end{tabular}

Conversion: SI to traditional units - Testosterone: $1 \mathrm{nmol} / \mathrm{l} \approx 0.29 \mathrm{ng} / \mathrm{ml}$. Androstenedione: $1 \mathrm{nmol} / \mathrm{l} \approx 0.28 \mathrm{ng} / \mathrm{ml}$. Dehydroepiandrosterone sulphate: $1 \mu \mathrm{mol} / \approx \approx 0 \cdot 43 \mu \mathrm{g} / \mathrm{ml}$.

TABLE III-Iterative pulse analysis of data on luteinising hormone in the two groups of patients

\begin{tabular}{|c|c|c|c|c|c|}
\hline \multirow{2}{*}{$\begin{array}{l}\text { Case } \\
\text { No }\end{array}$} & \multirow{2}{*}{$\begin{array}{l}\text { No of pulses } \\
\text { detected }\end{array}$} & \multirow{2}{*}{$\begin{array}{c}\text { Sampling } \\
\text { time } \\
\text { (h) }\end{array}$} & \multicolumn{2}{|c|}{ Luteinising hormone $(\mathrm{IC} 1)$} & \multirow{2}{*}{$\begin{array}{l}\text { Cycle on spectral } \\
\text { analysis } \\
\text { (min }\end{array}$} \\
\hline & & & Range & Mean & \\
\hline \multicolumn{6}{|c|}{ Subclinical primary testicular failure ${ }^{\star}$} \\
\hline 1 & 4 & 8 & $6-12$ & 10 & 240 \\
\hline 2 & 5 & 8 & $8-17$ & $14 \cdot 6$ & 240 \\
\hline 3 & 6 & 8 & +-12 & $8 \cdot 7$ & 240 \\
\hline 4 & 5 & 6 & $6-15$ & 9 & 120,240 \\
\hline \multicolumn{6}{|c|}{ Ozert gonadal failure $†$} \\
\hline 5 & 1 & 6 & $3-4$ & $3 \cdot 6$ & ND \\
\hline 6 & & 8 & $5 \cdot 0-6 \cdot 5$ & 6 & ND \\
\hline 7 & 1 & 8 & $3 \cdot 5-5 \cdot 0$ & 4 & ND \\
\hline 8 & 1 & 8 & $4 \cdot 5-5 \cdot 5$ & $5 \cdot 2$ & ND \\
\hline 9 & & 8 & $8 \cdot 0-9 \cdot 5$ & 9 & ND \\
\hline
\end{tabular}

$\mathrm{ND}=$ No appreciable pulses detected

*In the control group the mean number of pulses was five and the mean luteinising hormone concentration was $5 \cdot 6$ (range 3-8) IU/1.

In the control group the mean number of pulses was four and the mean luteinising hormone concentration was $6 \cdot 4$ (range $4 \cdot 0-8 \cdot 5$ ) IU 1 .

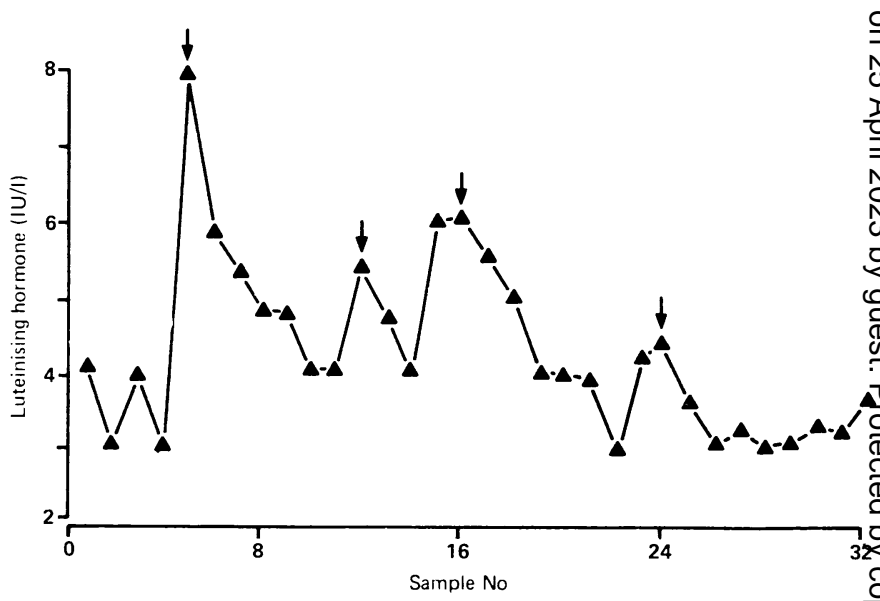

FIG 2-Pulsatility of luteinising hormone in a healthy control. Arrows indicat appreciable pulses as determined by iterative computerised analysis. 


\section{Results}

\section{ANDROGENS (table II)}

All nine patients had the pattern of androgen disturbance reported previously for similar groups of patients ${ }^{1011}$-namely, low testosterone, low dehydroepiandrosterone sulphate, and raised androstenedione concentrations.

\section{LUTEINISING HORMONE CONCENTRATION}

The mean concentration of luteinising hormone was higher in the patients with subclinical primary testicular failure than in their controls $(10.6 v 5.6$ $\mathrm{IU} / 1 ; \mathrm{p}<0.05$ ). The mean concentration did not differ significantly between the patients with overt hypogonadism and their controls $(5.5 v 6.4 \mathrm{IU} / \mathrm{l})$.

\section{PULSE ANAL YSIS (table III)}

Iterative analysis - The ratio of signal to noise exceeded 5:1 in all cases. Appreciable pulses of luteinising hormone were identified in all the patients with subclinical primary testicular failure and their matched controls. No significant difference was seen in the number of pulses. The amplitude of the pulses tended to be increased in the patients, but this trend did not reach significance (figs 2 and 3). In contrast the release of luteinising hormone in

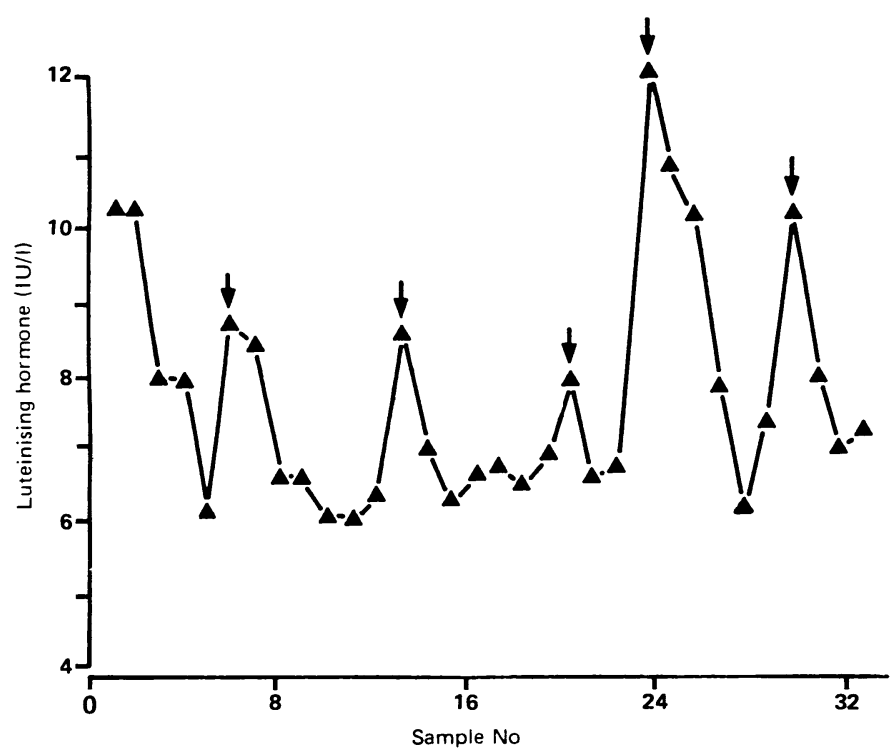

FIG 3-Pulsatility of luteinising hormone in patient with alcoholic liver disease but no hypogonadism. Arrows indicate appreciable pulses as determined by iterative computerised analysis.

the patients with overt hypogonadism was attenuated. A single pulse was seen in three patients, and no pulses were seen in two (patients $v$ controls $\mathrm{p}<0.01$; fig 4).

Spectral analysis-All four patients with subclinical primary testicular failure and their controls showed release of luteinising hormone with a frequency of 240 minutes. One patient also showed release with a frequency of 120 minutes. None of the five men with overt hypogonadism showed a low frequency release of luteinising hormone.

\section{Discussion}

Our study showed two patterns of release of luteinising hormone in men with chronic alcoholic liver disease. In those men with no clinical signs of hypogonadism (cases 1-4) pulsatility of luteinising hormone was preserved and mean concentrations of the hormone were increased. This is the pattern of release seen in primary testicular failure and may reflect a normal response of luteinising hormone to the reduced testosterone concentrations. ${ }^{12}$ In the men with overt gonadal failure (cases 5-9) the release of luteinising hormone was severely attenuated and mean concentrations of the hormone were not raised. This is the pattern seen in hypogonadism of "hypothalamic origin"-for example, secondary to hyperprolactinaemia. ${ }^{6}$ In this second group androgen concentrations did not differ significantly from those in the group with subclinical primary testicular failure, and thus the impaired release of luteinising hormone is presumptive evidence for impaired hypothalamic control.

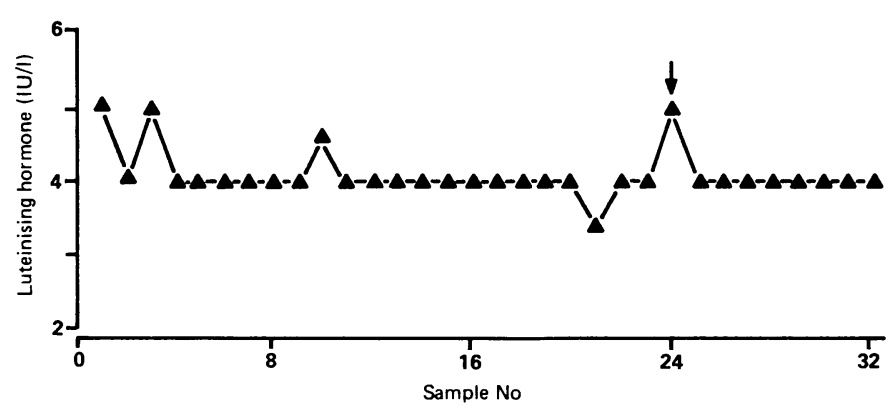

FIG 4-Pulsatility of luteinising hormone in patient with alcoholic liver disease and clinical hypogonadism. Arrows indicate appreciable pulses as determined by iterative computerised analysis.

Spectral analysis showed the release of luteinising hormone in healthy controls to have a cycle of 240 minutes; this pattern of release was preserved in the men with alcoholic liver disease without hypogonadism. In the group with overt gonadal failure this pattern of release was lost, providing further evidence for a hypothalamic defect.

From the present data we cannot implicate liver disease per se in the reduction of pulsatility of luteinising hormone. Abnormal pulsatility of the hormone (as determined by radioimmunoassay) has recently been shown in other chronic diseases such as chronic renal failure, ${ }^{13}$ though, interestingly, in renal disease the function of bioactive luteinising hormone seems to be preserved. In healthy men acute alcohol consumption does not significantly alter pulsatility of luteinising hormone, ${ }^{14}$ but daily consumption may have a different effect in those destined to become alcoholic.

This work was supported by the locally organised research fund of Leeds Area Health Authority (grant No LE59). Computer programs were kindly supplied by Dr R A Steiner (University of Washington, United States) and Dr A P Murdoch (University of Newcastle).

\section{References}

1 Boyden TW, Pamenter RW. Effects of ethanol on the male hypothalamic-pituitary-gonadal axis. Endocr Rev 1983;4:389-95.

2 Valimaki $H$, Harkonen $M$, Ylikahri R. Acute effects of alcohol on female sex hormones. Alcoholism (NY) 1983;7:289-93.

3 Van Thiel DH, Lester R, Snervis RJ. Hypogonadism in chronic liver disease: evidence of a double defect. Gastroenterology 1974;67:1188-99.

Van Thiel DH, Lester R, Vaitukais J. Evidence for a defect in pituitary secretion of luteinizing hormone in chronic alcoholic men. F Clin Endocrinol Metab 1978;47:499-507.

5 Mowat NAG, Edwards CRW, Fisher R, McNeilly AS, Green JRB, Dawson AM. Hypothalamic pituitary function in men with cirrhosis of the liver. Gut 1976;17:345-50.

6 Winters SJ, Troen P. Altered pulsatile secretion of luteinizing hormone in hypogonadal men with hyperprolactinaemia. Clin Endocrinol (Oxf) 1984;21:257-63.

7 Bannister P, Sheridan P, Losowsky MS. Plasma concentrations of sex hormones in post menopausal women with non-alcoholic cirrhosis. Clin Endocrinol (Oxf) 1985;23:335-41.

8 Clifton DK, Steiner RA. Cycle detection: a technique for estimating the frequency and amplitude of episodic fluctuations in blood hormone and substrate concentrations. Endocrinology 1983;112:1057-64.

9 Murdoch AP, Diggle PJ, Dunlop W, Kendall-Taylor P. Determination of the frequency of pulsatile luteinizing hormone secretion by time series analysis. Clin Endocrinol 1985;22:341-6.

10 Gordon GC, Oliver J, Rafii F, Southren A Conversion of androgens to estrogens in cirrhosis of the liver. $\mathcal{F}$ Clin Endocrinol Metab 1975;40:1018-26.

11 Franz $C$ watson D, Longcope C. Estrone sulphate and dehydroepiandrosterone sulphate in normal subjects and men with cirrhosis. Steroids 1979;84:563-73.

12 Winters SJ, Troen P. A reexamination of pulsatile luteinizing hormone secretion in primary testicular failure. 7 Clin Endocrinol Metab 1983;57:432-5.

13 Rodger RSC, Morrison L, Dewar JH, Wilkison R, Ward MK, Kerr DNS. Loss of pulsatile Rodger RSC, Morrison L, Dewar JH, Wilkison R, Ward MK, Kerr DNS. Loss of pulsatile
luteinising hormone secretion in men with chronic renal failure. Br Med J 1985;291:1598-600. 14 Bannister P, Handley T, Chapman C, Losowsky MS. LH pulsatility in healthy men following acute ethanol ingestion. Clin Endocrinol (in press).

(Accepted 5 August 1986) 